\title{
To label or not to label: balancing the risks, benefits and costs of mandatory labelling of GM food in Africa
}

\author{
Jessica Oh ${ }^{1,3}$ and Obidimma C Ezezika ${ }^{1,2,3,4^{*}}$
}

\begin{abstract}
There seems to be growing controversy among interest groups worldwide about whether genetically modified (GM) foods need to be labelled. There are also growing concerns, particularly among civil society groups, about the potential danger of GM foods, for which labels are being demanded. Particularly in Africa, the issue of labelling GM foods requires attention due to the rapid growth of agricultural biotechnology initiatives. Using Kenya as a case study, and based on interviews with key agricultural stakeholders and a review of the literature, we present five points to consider in discussions on how the need for mandatory GM labelling should be assessed. This framework encompasses, and is underpinned by, important considerations about ethics, consumer autonomy, costs, stigmatization, feasibility and food security as they pertain to agricultural biotechnology.
\end{abstract}

Keywords: agricultural biotechnology, genetically modified food, labelling, mandatory, Africa, Kenya

\section{Introduction}

Labelling of genetically modified (GM) foods has become an issue requiring attention in Africa due to the rapid growth of public-private partnerships operating agricultural biotechnology initiatives. Since partners must adhere to a given country's laws on biosafety and labelling, it is imperative that countries are also clear about the stipulations outlined in any GM labelling law as there is much concern among the private sector in Africa - be it warranted or not - that labels on GM products will raise fear and suspicion among the public and thereby stymie acceptance of agricultural biotechnology in the continent.

In our latest social audit ${ }^{\mathrm{a}}$ engagement with one such initiative, the Water Efficient Maize for Africa (WEMA) project, we asked key agricultural stakeholders ${ }^{\mathrm{b}}$ about any regulatory challenges facing the WEMA project. Among their responses, some stakeholders - particularly seed companies - voiced concern about the implications of the GM labelling regulations recently introduced in Kenya for

\footnotetext{
* Correspondence: obidimma.ezezika@acild.org

${ }^{1}$ Sandra Rotman Centre, University Health Network and University of Toronto, Toronto, ON, Canada

${ }^{2}$ Dalla Lana School of Public Health, University of Toronto, Toronto, ON,

Canada

Full list of author information is available at the end of the article
}

both the progress and future role of these initiatives. The WEMA project is a public-private partnership that involves funding partners such as the Bill \& Melinda Gates and Howard G Buffett Foundations, as well as partner institutions such as the African Agricultural Technology Foundation, International Maize and Wheat Improvement Center, Monsanto, and national agricultural research systems in five African countries (Kenya, Mozambique, South Africa, Tanzania and Uganda). The goal of the partnership is to develop drought-tolerant and insect-protected maize and make these varieties available royalty-free to smallholder farmers in sub-Saharan Africa through seed companies. ${ }^{\mathrm{c}}$

For the past decade, the introduction of GM ingredients in food products has been at the centre of highly controversial and polarizing debates in many countries. Because there is a wide gap between scientific judgment and public opinion on GM food, governments are confronted with the dilemma of how to regulate the marketing of GM food products. One option for regulating GM foods is to permit them but ensure segregation from their conventional counterparts, which implies creating two separate production tracks and introducing a labelling scheme to allow consumers to choose between GM and non-GM food products [1]. However, the choice of
Ciomed Central

(c) 2014 Oh and Ezezika; licensee BioMed Central Ltd. This is an Open Access article distributed under the terms of the Creative Commons Attribution License (http://creativecommons.org/licenses/by/2.0), which permits unrestricted use, distribution, and reproduction in any medium, provided the original work is properly credited. 
the labelling scheme, mandatory or voluntary, is not uniform across countries. During the last decade, over 40 countries globally have required GM products to be labelled [2]. Some countries, such as the United States and Canada, have opted for a voluntary labelling scheme, while other countries such as European Union (EU) member states, Japan and Australia have opted for a mandatory labelling scheme, arguing that consumers have the right to know [3].

The issue of labelling GM foods has begun to gain salience in East Africa, specifically in Kenya, where GM crops are in the process of gaining approval for commercial production. We assess the cogency and practicality of the arguments for and against GM food labelling by using Kenya, which introduced mandatory GM labelling in May 2012, as a case study.

The debate on labelling of GM food products encompasses complex issues that are entangled in conflicting interests and beliefs about the production, consumption and implications of GM foods, as well as ethical concerns such as those over consumers' right to know what is in their food. We posit in this paper that the arguments underpinning the imperative to label GM foods need to be assessed within a framework in which ethics, consumer autonomy, costs, stigmatization, feasibility and food security are all considered. Based on the concerns about GM labelling raised by some stakeholders in our 2012 Social Audit, we seek to explore the logic behind these arguments to allow for an understanding of the implications of mandatory GM labelling in the context of Africa.

\section{GM labelling regulations in Africa Current status}

To date, Burkina Faso, South Africa, Egypt and Sudan are the only African countries that have approved biotech crops for commercial production [4,5]. Nigeria, Kenya and Uganda currently have GM crops under confined field trials [4]. Of the aforementioned countries, only South Africa and Kenya have regulations for GM labelling in place.

In South Africa, the regulations governing the labelling of foods containing genetically modified organisms (GMOs) is outlined in Section 24 of the Consumer Protection Act, 2008 (No 68 of 2008) [6], which was signed into law on 24 April 2009 and came into effect on 31 March 2011 [7]. The Act sets out the minimum requirements to ensure adequate consumer protection and provides an overarching framework for all other laws that provide for consumer protection. Under the Act, Regulation 293 makes a provision for a 'may contain genetically modified ingredients' clause, which relieves companies from labelling foods if it is 'scientifically impractical or not feasible to test foods' for the presence of GMOs or GM ingredients [8]. On
9 October 2012, the Department of Trade and Industry published draft amendments to the Consumer Protection Act stipulating that all imported or locally produced food containing $5 \%$ or more GM components or ingredients must now be labelled as 'contains genetically modified ingredients or components' [9].

In 2009, Kenya passed the Biosafety Act, No 2 of 2009, which allows for commercialization of GM crops [10]. The Government of Kenya (GOK) first required the GM content of foods, feed or ingredients to be identified on product labels in 2010 when the Kenya Bureau of Standards published regulation KS 2225:2010 [11]. Most recently, the GOK, through Kenya Gazette Supplement No 48 of 2012, ${ }^{\text {d }}$ introduced additional requirements on GMcontaining foods - which are referred to as the 'Biosafety (Labeling) Regulations, 2012' [12]. In particular, the new regulations stipulate the following: 1) a reduction of the adventitious presence of unapproved events from 5 to $1 \%$, 2) use of 'GMO-Free' labelling can only be used where the GM adventitious presence is below a $1 \%$ threshold, 3) labels should refer to the GM content in the same font size used for the other ingredients and trademarks, and 4) references to the CODEX Standard CAC/GL 762011 [11]. Violation of the newly gazetted regulations carries a fine of up to 20 million Kenyan shillings (approximately US $\$ 235,300$ ) and/or imprisonment of up to ten years [12].

\section{Reaction to the newly introduced GM labelling regulations in Kenya}

Reactions to the new labelling regulations in Kenya are diverse, and have sparked intense public debate among pro- and anti-GM actors alike. We herein provide a general picture of what the public debate looks like and the various stakeholders who have voiced their views based on media reporting on the new labelling regulations in Kenya. Some in Kenya call the new regulations a 'victory' and 'consumer rights milestone' [13], as those in favour of the regulations usually assert that Kenyans have a 'right to know' what goes in their food and should be 'protect[ed]' [14].

On the other hand, millers are calling for an urgent review of the new regulation, which they claim is too prohibitive and likely to cause food shortages in the country. They argue that they will incur additional costs to meet the labelling requirements, which will have to be passed on to consumers, and that the new regulation will curtail free and fair trade in GM foods [15]. Kenyan scientists working in the field of biotechnology research have criticized the new regulation for lacking a scientific basis [16]. Experts and politicians have warned that such labelling may increase food prices, thereby hindering efforts to address food security needs in the country [15]. 


\section{Balancing the interests at stake: five points to consider}

Based on the reactions above, it is evident that the views of certain stakeholders are in conflict. Biased though these views may be, there will inevitably exist conflicting interests. For one, some consumers may continue to demand labels, and food companies - particularly millers - will continue to insist that labels will increase their costs. We outline the current debate and the conflicting - and often diametrically opposed - opinions and views on GM food labelling in the form of a number of points. We then explain how these competing interests can be woven into the discussion on GM food labelling regulations.

\section{Right to know and consumer autonomy}

Many have defined the rationale for GM labelling strictly as a 'right to know' issue - that consumers have a right to know what is in the foods they purchase. Embedded in the right-to-know argument is the notion of autonomy: GM labels allow consumers to exercise their freedom to choose (and avoid) which foods to purchase - be it GM, organic or conventional [17]. Many studies have unpacked GM labelling in terms of consumer autonomy [18-20]. Similarly, proponents of GM labels believe that labelling highlights the value of transparency by honouring all concerns about GM foods along a range of perspectives - from health or allergen to moral and religious [21]. Respecting consumers' autonomy of choice does not necessarily mean, however, that someone (e.g., producers, retailers or public authorities) is morally obliged to ensure that both GM and non-GM food products are available in the market $[18,22]$.

On the other hand, this insistence on a right to know whether foods have been produced with GM ingredients seems to stem from the fear and uncertainty among the public about the unknown health and environmental effects of GM foods. According to proponents of mandatory GM labelling, labelling of new products - such as GM foods - that currently have no known risk of adverse effects to human health is a moral imperative from the viewpoint of public health ethics [21]. For example, antiGM activists usually corroborate their claims with research that has shown that GM food is harmful to human health, such as the published study by French researchers showing evidence of cancer tumours in rats fed a diet of Monsanto's GM maize NK603 [23,24]. This study was immediately criticized by scientists, who mentioned a number of methodological problems - its small sample size, the chosen breed of rats (which are predisposed to developing tumours) and that the tumour rates did not increase in proportion to the dose of GMOs fed to the rats $[25,26]$. These findings also contradict those of other long-term studies in which GM foods were fed to a wide range of lab animals. Snell et al. [27] published a review of 24 similar long-term studies and concluded that those studies do not provide evidence of health hazards. In particular, when many in the scientific community and agencies such as the European Food Safety Authority have concluded that the study is of 'insufficient scientific quality to be considered as valid for risk assessment' [28], such studies should not serve as a valid guide to the safety of GM foods.

While consumer autonomy is the long-familiar rationale for GM labelling, some also argue that consumer choice and autonomy do not justify mandatory labelling of GM foods. Michael Reiss, for example, suggests that the principle of choice should be held both at the level of retailers and at the level of individual consumers: consumers who insist on knowing whether their food contains GMOs will seek out retailers that label and consumers who do not have a deep interest in knowing such information will not seek GM labels [29]. Similarly, Hansen argues that it is not obvious that autonomy by itself justifies mandatory labelling: 'Consumers have all the information they need if they simply assume that every product that is not specifically labelled "GM-Free" or "organic" may contain GM ingredients' [22].

Further, while GM labels have the potential to contribute positively to consumer education and awareness - as has been the case with nutrition labels - some argue that GM labels are only useful for the consumer who already reads the ingredients list. Gruere et al. state, 'Information concerning GMO content in a parenthesis in the ingredients list is not very likely to catch the eye of the average consumer' [3]. In South Africa, for example, in which a mandatory labelling law recently superseded the voluntary labelling scheme, and despite significant levels of GM food crop production in the country, the majority of South Africans are not aware of the existence of GM foods, nor are they aware that they are consuming GM foods [30]. Given studies such as this one, we suggest that, while GM labels can potentially increase consumer awareness about GMOs, improving consumers' knowledge and awareness of agricultural biotechnology can facilitate consumers' interpretation of GM labels, thereby maximizing the benefits - that is, choice and information - consumers obtain from labels.

Chris Macdonald deconstructs the right-to-know argument and points to the flip side by asking: are agri-food companies ethically obligated to provide labels? Macdonald, focusing on the Canadian context, argues that individual companies do not have an ethical obligation toward consumers to label their GM foods: 'although unilateral action in this regard might be admirable, an agri-food company has no ethical obligation to label its GM foods, given the current social, legal, scientific, and economic context' [31]. In other words, the lack of any scientific research showing that GM foods are harmful to human health makes moot the ethics argument: since 
GM foods have thus far been proven to be safe, companies are not acting unethically if they fail to provide labels on their GM products.

\section{Costs}

A mandatory GM labelling law makes imperative a discussion about the costs of implementation. Labelling GM foods entails much more than the mere production of a sticker or label indicating the presence of GM ingredients; the different procedures that must be fulfilled at various stages of the entire food production chain potentially impose costs on farmers, traders, manufacturers, the government and, ultimately, consumers. These include the technicalities of grain production, handling, processing and storage. One study found that the bulk of costs incurred would be from measures of segregation and identity preservation to prevent or limit mixing within the non-GM supply chain [32]. In a study examining the economic effects of GMO regulations, Bullock and Desquilbet found that tolerance levels are a 'key element of costs of non-GMO segregation, and zero-tolerance levels may be impossible to obtain without major organizational and economic costs' [33]. Another study, however, shows that there is an insignificant difference in the number of products requiring GM labelling when comparing a threshold level of GM material of $1 \%$ and $5 \%$ [8]. The different results from these studies may be attributed to the difference in the countries examined.

Many, especially agri-food companies and food manufacturers, point out the significant costs involved in mandatorily labelling GM products. For example, a study conducted to capture the perspectives of major stakeholders in the Kenyan food industry concluded that, while most respondents deem important the traceability of GM products and ingredients, many do not support labelling of GM products because of the associated extra costs and the possibility of negative reactions from consumers [34]. While there have been studies done [5,35,36], though all ex ante, showing that mandatory labelling will create additional costs that will eventually be passed on to the consumer, actual increases in food prices due to mandatory GM labelling have not yet been reported. One study based on the current EU regulations in 2001 found that mandatory GM labelling results in an added per capita annual cost of approximately US $\$ 0.23$ [37].

There is a need for more case-by-case assessments about the economic costs implied by mandatory GM labelling to obviate unsubstantiated claims verbalized by the food industry. Nevertheless, consumers should not accept, at face value, statements made by leaders in the food industry conveying that consumers will bear the costs of GM labels - which are often not impartial. The 'cost' argument seems to be overemphasized by the GM food industry to avoid the real fear of stigmatization - which we discuss in the next section. African governments can therefore benefit from credible assessments that allow them to determine the economic viability of regulating the mandate within their respective countries before introducing a labelling law, as well as to determine which stakeholders may actually be affected. More studies assessing the potential economic costs of mandatory labelling in Africa, however, are needed, since most of the cost experiments done pertaining to mandatory GM labelling are based on the experiences of countries outside of Africa.

\section{Stigmatization}

Opponents of mandatory GM labelling - which usually includes the agri-food industry - deem such labels as stigmatizing a product that does not deserve to be treated so. Moreover, our latest Social Audit of the WEMA project has revealed that the issue of labelling GM foods - particularly, the stigmatization of GM products and the potential impact on the cost of WEMA seeds - is a concern to stakeholders, particularly seed companies [38]. Regardless of whether or not these views are valid or authoritative, we included a discussion about stigmatization because it seems to underlie the biotech food industry's overall opposition to GM labels.

Stigma is defined as 'a mark placed on a person, place, technology, or product associated with a particular attribute that identifies it as different and deviant, flawed or undesirable', such that the perceived consequences of using a product or service 'exceed the direct physical harm to human beings and ecosystems to include more indirect effects on the economy, social institutions and well-being' [39]. Stigma is associated with negative attributions about the source of the mark, and there is indeed evidence that genetic modification is cognitively linked to negative objects and attributes - such as tampering and artificiality - and to concepts such as danger [40]. Baker and Burnham [41] suggest that mandatory labelling may raise concerns among consumers about GM foods and therefore stigmatize them, and raise the biotech food industry's fears about consumer rejection. This argument seems to suggest that ignorance of food ingredients is synonymous with acceptance of GM food products; however, it is not an unwarranted point given the widespread negative perceptions of GMOs.

As it stands, GM food labels have no relation to the safety of GMOs but are used to provide consumer choice. But given the current sociopolitical context in many African countries, labels on GM products at this time could give the impression of a possible danger, and, in turn, imply falsely that something is wrong with them. For example, some bring up the 'guilt by association' argument - that GM labels, particularly in the current climate, give the false impression that the food is less safe than conventional foods; conversely, a 'GMO-free' label may imply 
that such foods are safer or better than foods containing GMOs [42]. In such cases, the disclosing of GM ingredients through labelling may be more misleading than informative.

It has also been said that the stigmatizing of GM products that ensues from such impressions can significantly affect the efficiency of the market by reducing demand for GM products or inflating demand for their counterparts (conventional and organic) [39]. And there seems to be no significant difference in the reactions induced by a positive (e.g., 'contains GMOs') or negative (e.g., 'non-GMO') label - both have the potential to give rise to negative perceptions about GM foods [39]. One experimental study showed that consumers perceive GM labels as a negative signal, and that labels may therefore lower the expected market share of GM foods [43]. This is a problem because it implies that the labels on GM foods are not adequately and accurately informing consumers. Mandatorily labelling all food - to convey whether it is GM, organic or conventional (e.g., treated with pesticides) - may seem to be a logical solution to avoid stigmatizing only GM foods. Yet, in a context characterized by sensational reporting on GM foods and increasing anti-GM movements around the world, and in which it is increasingly recognized that 'organic' labels are used more for marketing purposes than to inform consumers, the foods labelled as 'GM' will be seen as least desirable; in this way, labels on GM foods can be considered stigmatizing.

While significant panels such as the World Health Organization, the International Council for Science and the Food and Agricultural Organization - to name a few have reached the conclusion that GM foods do not pose risks to human health [44-46], media sensationalism and anti-GM activists continue to raise consumer fears by disregarding or downplaying the current scientific evidence on GM foods. Against this sort of backdrop, 'GM' labels can perpetuate and exacerbate fear of GM foods and engender more confusion. At the same time, when the biotech food industry amplifies the cost aspect of GM labels, they may be placing GMOs in a more undesirable light by adding to consumers' negative perceptions: not only may GM foods be unsafe for human consumption, but they may now be more expensive if they are labelled - the cost of which consumers will have to bear.

\section{Feasibility}

What is perhaps most germane in the African context is assessing the feasibility of labelling GM produce sold in informal markets such as open-air and roadside markets. These informal markets are crucial for household food security: they provide a direct source of income for the low-income vendors that run them; are an important outlet for small producers due to the less stringent requirements for product quality and packaging; and are an especially important outlet for poor consumers in both urban and rural areas because of familiarity, greater accessibility and ability to buy in smaller quantities [47]. It is unclear how the new regulations for GM labelling in Kenya will be enforced for the unpackaged produce sold in informal markets - though, there is mention that for products that are not pre-packaged, 'the words "genetically modified organisms" or "genetically modified (name of organism)" shall appear on, or in connection with, the display of the product' [12]. However, Kenya's new labelling regulations do not apply to foods sold by restaurants and food vendors. In Kenya's Biosafety (Labelling) Regulations, 2012, section 5d states that these regulations shall not apply to 'food intended for consumption prepared and sold from food premises and vendors' [12]. These regulations also state that the objectives thereof are a) to ensure that consumers are made aware that food, feed or a product is genetically modified so that they can make informed choices; and b) to facilitate the traceability of genetically modified organism products to assist in the implementation of appropriate risk management measures where necessary' [12]. It is unclear whether the exemption will apply to food vendors at open-air markets and roadside kiosks. If it does not, the implication is slightly concerning: the majority of the rural and urban poor in Africa rely on informal retail markets to obtain staple products and fresh produce, which means many people would not have access to GM labels and are thus left uninformed about whether their food is genetically modified.

\section{Impact on food security and innovation}

Studies on whether GM labels implemented in Kenya will increase the cost of food have yet to be done. Should GM labels increase costs, however, access to food will be negatively affected. Like the EU member states, many African governments have chosen to follow the precautionary approach toward regulating GM foods and crops, for reasons ranging from cultural ties and agricultural trade relations to the amount of bilateral foreign assistance Africa receives from Europe [48]. But the circumstances of Africa are very different than those of Europe. In Africa, the percentage of the population that might benefit directly from GM crops is much higher than in Europe, because $60 \%$ or more of all Africans are still farmers who depend directly on agriculture for income and subsistence, while farmers in Europe are highly productive even without using GM crops [48].

Innovations such as crop biotechnology offer one potential solution to combating hunger and malnutrition in developing regions. Without innovation in agriculture, the Green Revolution, for example, would never have achieved the remarkable success it did in Asia in contributing to a substantial increase in food production and reducing poverty. The private sector, through public-private 
partnerships, is already investing heavily in the research and development of biotech crops that will improve agricultural productivity in Africa. For example, the WEMA project has been firmly established in Kenya, South Africa and Uganda - among five participating countries - and is close to achieving its goal of providing small-scale farmers with drought-tolerant maize varieties. Maize is a staple food for over 300 million people in sub-Saharan Africa, many of whom are themselves growers of maize [48]. In Kenya, maize is important for both food security and income generation for almost $90 \%$ of the rural population [49], and drought-tolerant varieties are one response to population growth, unreliable rainfall and climate change - factors expected to increase drought risks to maize growers in Africa in the future [48].

\section{Discussion}

The points we outline in the paper are not to be understood as comprising an argument against mandatory labelling of GM foods or in support of GM crop development. Instead, our aim is to highlight, in light of the concerns raised by some stakeholders in our latest Social Audit of the WEMA project, the important task facing African governments of carefully weighing all the issues at stake in the debate over labelling GM foods. In particular, governments need to find a way to resolve the perceived conflict between their introduction of mandatory labelling laws which seemingly hinder GM crop production - and their ambitious food security agendas that stress the need to invest in agricultural biotechnology.

In North America, widespread use and consumption of GM foods occurred before any debate about GM labelling even began. Consumers in African countries such as Kenya, however, have a chance to take part in, and shape, the debate on GM labelling as the introduction of GM foods is a relatively new phenomenon in Africa. That African governments seem inclined to take the precautionary approach to introducing GM foods and mandating labels is a rational move amidst the uncertainty surrounding the public health impact of GM foods and for safeguarding their agricultural exports to European markets. However, agricultural stakeholders for the most part interpret labelling regulations as implicit opposition by some key decision-makers within government to GM food production [50], which contributes to misunderstandings, accusations and perceived stigmatization. While the GOK's introduction of GM labelling regulations is commendable, it is equally important that the government consults various agricultural stakeholders so that the latter know whether, and how, they will be affected.

Many of the arguments put forth in favour of and against mandatory GM labelling appear to be ad hominem. The pro-labelling/anti-GMO group overemphasizes the 'right to know' aspect of GM labelling, perhaps to avoid supplying hard evidence that supports a 'real need' for labelling. The biotech industry, on the other hand, overemphasizes the cost aspect of GM labels, perhaps to avoid the real fear of stigmatization and, in turn, consumer rejection of GM food products. We believe it is beneficial for governments to consider the five points introduced in this paper to obviate perceptions of discriminating against or benefiting a particular group of stakeholders, which, we hope, will contribute to minimizing the spread of misinformation concerning agricultural biotechnology.

\section{Endnotes}

${ }^{a}$ Social auditing is a process whereby an audit team collects, analyses and interprets descriptive, quantitative and qualitative information from stakeholders to produce an account of a project's ethical, social, cultural and commercialization performance and impact.

${ }^{\mathrm{b}}$ Key agricultural stakeholders' here refer to stakeholders of the WEMA project whom we interviewed to produce the annual Social Audit reports from 2009 to 2012. For each report, the viewpoints of 100 people from across the five WEMA countries (Kenya, South Africa, Mozambique, Tanzania and Uganda) were collected using a quantitative questionnaire and a semi-structured interview guide. The people interviewed fell under the following stakeholder groups: technical resource and consultant; academics and scientists; legal; agricultural extension services; agricultural commercial enterprises; farmers' associations; technology funders; science and technology government departments; national agricultural research systems; regional organizations working with small-scale farmers; public/NGOs for public concerns; media; regional national authorities; project regional personnel and seed companies.

${ }^{\mathrm{c}}$ To learn more about the WEMA project, see [51].

${ }^{\mathrm{d}}$ Full title of the gazette: Kenya Gazette Supplement No 48 of 2012, Legal Notice No 40 (dated 25 May 2012).

\section{Abbreviations \\ GM: genetically modified; GMO: genetically modified organism; GOK: Government of Kenya; WEMA: Water Efficient Maize for Africa.}

\section{Competing interests}

The Sandra Rotman Centre, through the Ethical, Social, Cultural, and Commercialization $\left(E_{S C}^{2}\right)$ Program, received funding from the Bill \& Melinda Gates Foundation to evaluate (i.e., conduct a social audit on) the WEMA project mentioned in the paper.

\section{Authors' contribution}

OCE was responsible for the conception and design of the study, and for data collection. JO was responsible for the literature review and writing up of the manuscript. JO and OCE participated in analysis and interpretation of results. Both authors read and approved the final manuscript.

\section{Acknowledgements}

This study was funded by the Bill \& Melinda Gates Foundation and supported by the Sandra Rotman Centre, an academic centre at the 
University Health Network and University of Toronto. The findings and conclusions contained within are those of the authors and do not necessarily reflect official positions or policies of the foundation. We would like to thank Jerome Singh for very helpful comments and suggestions on earlier drafts of the manuscript. We are also grateful to the two anonymous reviewers whose comments and suggestions helped improve and clarify this manuscript.

\section{Author details}

'Sandra Rotman Centre, University Health Network and University of Toronto, Toronto, ON, Canada. ${ }^{2}$ Dalla Lana School of Public Health, University of Toronto, Toronto, ON, Canada. ${ }^{3}$ African Center for Innovation and Leadership Development, Federal Capital Territory, Abuja, Nigeria. ${ }^{4}$ National

Biotechnology Development Agency (Federal Ministry of Science and Technology), Umar Musa Yar' Adua Way/Airport Road, Lugbe Area, Abuja, Nigeria.

Received: 21 May 2013 Accepted: 1 April 2014

Published: 23 April 2014

\section{References}

1. Dannenberg A, Scatasta S, Sturm B: Mandatory versus voluntary labelling of genetically modified food: evidence from an economic experiment. Agric Econ 2011, 42:373-386.

2. Gruere G, Rao S: A review of international labeling policies of genetically modified food to evaluate India's proposed rule. AgBioforum 2007, 10(1):51-64

3. Gruere G, Carter C, Farzin Y: What labelling policy for consumer choice? The case of genetically modified food in Canada and Europe. Can J Econ 2008, 41(4):1472-1497.

4. James C: Global Status of Commercialized Biotech/GM Crops: 2011. Ithaca, NY: ISAAA; 2011. Brief 43 .

5. James C: Global Status of Commercialized Biotech/GM Crops: 2012. Ithaca, NY: ISAAA; 2011. Brief 44

6. Republic of South Africa: No. 68 of 2008: Consumer Protection Act, 2008. Govern Gazette 2009, 526(32186):1-186. Date published: 9 April 2009.

7. The South African Institute of Chartered Accountants: Consumer Protection Act, No 68 of 2008. Last Updated 2 September 2013.

8. Viljoen CD, Marx GM: The implications for mandatory GM labelling under the Consumer Protection Act in South Africa. Food Control 2013, 31:387-391.

9. Republic of South Africa: Notice 824 of 2012: Draft amendment regulations on Consumer Protection Act Regulations, 2011. Government Gazette 2012, 568(№. 35776):1-8. Date published: 9 October 2012.

10. Republic of Kenya: The Biosafety Act, 2009, Kenya Gazette Supplement. Nairobi, Kenya: Government Printer; 2009.

11. USDA Foreign Agricultural Service: Kenya Agricultural Biotechnology Report, USDA FAS GAIN. Washington, DC: USDA FAS; 2012. Gain Report.

12. Republic of Kenya: Kenya Gazette Supplement No 48 of 2012. Govern Gazette 2012, Legal Notice No. 40

13. Mandatory GM labelling victory in Kenya: Mandatory GM labelling victory in Kenya. Consum Int 2012, 2 July 2012.

14. Were E: Label GMO foods activists demand. Star 2012, 17 October 2012.

15. Gichana A: GMO labels will raise food prices, experts say. Star 2012 21 August 2012

16. Achia G: Kenya scientists criticise regulation on GMO labeling. Afr STI News 2012, 2 July 2012.

17. Rubel A, Streiffer R: Respecting the autonomy of European and American Consumers: defending positive labels on GM foods. J Agric Environ Ethics 2005, 18:75-84.

18. Siipi $\mathrm{H}$, Uusitalo $\mathrm{S}$ : Consumer autonomy and availability of genetically modified food. J Agric Environ Ethics 2011, 24:147-163.

19. Carter C, Gruère G: Mandatory labeling of genetically modified foods: does it really provide consumer choice? AgBioforum 2003, 6(1-2):68-70

20. Klintman M: The genetically modified (GM) food labelling controversy: ideological and epistemic crossovers. Soc Stud Sci 2002, 32(1):71-91.

21. Lappe M: Labeling should be mandatory. Nat Biotechnol 2002, 20:1081-1082
22. Hansen K: Does autonomy count in favor of labeling genetically modified food? J Agric Environ Ethics 2004, 17(1):67-76.

23. Maina A: Kenyans have a right to know what they eat. Daily Nation 2012 14 October 2012

24. Séralini G, Clair E, Mesnage R, Gress S, Defarge N, Malatesta M, Hennequin $D$, de Vendômois J: Long term toxicity of a Roundup herbicide and a Roundup-tolerant genetically modified maize. Food Chem Toxicol 2012, 50(11):4221-4231.

25. Mestel R: Study points to health problems with genetically modified foods. Los Angeles Times; 2012. 20 September 2012.

26. Pollack A: Foes of modified corn find support in a study. New York Times; 2012. 19 September 2012.

27. Snell C, Bernheim A, Bergé J, Kuntz M, Pascal G, Paris A, Ricroch AE: Assessment of the health impact of GM plant diets in long-term and multigenerational animal feeding trials: a literature review. Food Chem Toxicol 2012, 50(3-4):1134-1148.

28. European Food Safety Authority (EFSA). http://www.efsa.europa.eu/en/ press/news/121004.htm.

29. Reiss M: Commentary: labeling GM foods - the ethical way forward. Nat Biotechnol 2002, 20:868

30. Botha G, Viljoen C: South Africa: a case study for voluntary GM labelling. Food Chem 2009, 112:1060-1064

31. MacDonald C, Whellams M: Corporate decisions about labelling genetically modified foods. J Bus Ethics 2007, 75:181-189.

32. Carter C, Gruere G, McLaughlin P, MacLachlan M: California's proposition 37: effects of mandatory labeling of GM food. Agric Resour Econ 2012, 15(6):3-8.

33. Bullock $D$, Desquilbet $M$ : The economics of non-GMO segregation and identity preservation. Food Policy 2002, 27:81-99.

34. Bett C, Ouma J, De Groote H: Perspectives of gatekeepers in the Kenyan food industry towards genetically modified food. Food Policy 2010, 35:332-340.

35. De Leon A, Manalo A, Guilatco FC: The cost implications of GM food labeling in the Philippines. Crop Biotech Brief 2004, IV(No. 2).

36. Jaeger WL: Economics Issues and Oregon Ballot Measure 27: Labeling of Genetically Modified Foods (EM 8817). Corvallis, OR: Oregon State University; 2002

37. National Economic Research Associates: Economic Appraisal of Option for Extension of Legislation on GM Labeling, A Final Report for the Foods Standards Agency of the United Kingdom. London, UK: NERA; 2001.

38. Social Ethical Cultural and Commercialization Program: WEMA 2011 Social Audit Report: Ethical, Social, Cultural, and Commercialization (ESC2) Audit Report for the Water Efficient Maize for Africa (WEMA) Project 2011. Toronto, Canada: Sandra Rotman Centre; 2012.

39. Ellen P, Bone P: Strained by the label? Stigma and the case of genetically modified foods. Am Market Assoc 2008, 27(1):69-82.

40. Verdurme A, Viaene J: Exploring and modeling consumer attitudes towards genetically-modified food. Qual Mark Res: Int J 2003, 6(2):95-110

41. Baker $G$, Burnham T: The market for genetically modified foods: consumer characteristics and policy implications. Int Food Agribus Manag $\operatorname{Rev} 2002,4(4): 351-360$

42. Eldred JS: Analysis \& perspective: labeling GMO-derived food ingredients: a recipe for misinformation. World Food Regul Rev 1999, 14:16.

43. Tegene A, Huffman W, Rousu M, Shogren J: The Effects of Information on Consumer Demand for Biotech Foods: Evidence from Experimental Auctions. Washington, DC: United States Department of Agriculture Economic Research Service; 2003. Technical Bulletin No. 1903.

44. Food and Agriculture Organization of the United Nations: The State of Food and Agriculture 2003-2004: Agricultural Biotechnology Meeting the needs of the poor? Rome, Italy: FAO; 2004.

45. Mantell K: WHO urges Africa to accept GM food aid. Sci Dev Net 2002, 30 August 2002

46. Persley G: New Genetics, Food and Agriculture: Scientific Discoveries - Societal Dilemmas. Paris, France: International Council for Science (ICSU); 2003:1-56.

47. McCullough EB, Pingali PL, Stamoulis KG: The Transformation of Agri-Food Systems: Globalization. Supply Chains and Smallholder Farmers: Routledge; 2008.

48. Paarlberg R: GMO foods and crops: Africa's choice. New Biotechnol 2010, 27(5):609-613. 
49. USAID: Staple Foods Value Chain Analysis: Country Report - Kenya. USAID; 2010.

50. Wedding K, Tuttle JN: Pathways to Productivity: the Role of GMOs for Food Security in Kenya, Tanzania, and Uganda. Center Strategic Int Stud; 2013.

51. Water Efficient Maize for Africa. Nairobi, Kenya: African Agricultural Technology Foundation (AATF); http://wema.aatf-africa.org/about-wemaproject.

doi:10.1186/2048-7010-3-8

Cite this article as: Oh and Ezezika: To label or not to label: balancing the risks, benefits and costs of mandatory labelling of GM food in

Africa. Agriculture \& Food Security 2014 3:8.

\section{Submit your next manuscript to BioMed Central} and take full advantage of:

- Convenient online submission

- Thorough peer review

- No space constraints or color figure charges

- Immediate publication on acceptance

- Inclusion in PubMed, CAS, Scopus and Google Scholar

- Research which is freely available for redistribution 